\title{
A COMPARATIVE STUDY BETWEEN ENDONASAL ENDOSCOPIC AND MICROSCOPIC TRANSSPHENOIDAL APPROACHES IN MANAGEMENT OF PITUITARY ADENOMAS
}

\author{
By
}

\section{Osama Abd El-Kader Mohamed El-Moursi, Abd El-Baset Ali Saleh and Magdy Al-Hawary}

Department of Neurosurgery, Faculty of Medicine, Al-Azhar University

Corresponding author: Osama Abd El-Kader Mohamed El-Moursi,

E-mail: osama_abdelkader@gmail.com

\begin{abstract}
Background: Advances in the era of modern micro-neurosurgery enabled a reduction of surgical invasiveness and brain retraction which has been defined as minimally invasive or keyhole surgery. Sinonasal endoscopy has brought radical changes in the concepts of pathophysiology and treatment of sinonasal diseases as well as surgical techniques.
\end{abstract}

Objective: Assessment of patient outcomes regarding transsphenoidal endoscopic and microscopic approaches of pituitary adenomas.

Patients and methods: Our study included 40 cases of pituitary adenomas, operated upon during 2 years, half of them (group A; 20 cases) underwent endoscopic endonasal transsphenoidal pituitary adenoma resection, while the remaining (group B; 20 cases) operated upon using the standard microscopic transseptal transsphenoidal pituitary adenoma resection.

Results: The highest age incidence of our cases was during the third and fourth decades of life, with a male to female ratio of nearly $1: 1$. Headache was the commonest presenting symptom in our series both in endoscopic and microscopic groups; $(60 \% \& 70 \%)$ respectively followed by visual impairment; $(55 \% \&$ $60 \%$ ). Although, loss of libido was the most common endocrinopathies; (75\%\& 60\%) respectively. In our study CT-sella with coronal cuts was the initial radiographic investigation, performed in all our cases. It gave an idea about bony anatomy of the sella, sphenoid sinus, and particularly was important in showing the position of the sphenoid sinus septum, which was crucial in planning the decision of operation. In our study, improvement in out-come was higher in endoscopic group opposed to microscopic group (100\% vs. $71 \%$ improved headache, $82 \%$ vs. $58 \%$ visual improvement and $80 \%$ vs. $55 \%$ total tumor removal ).

Conclusion: Endoscopy offers a very special and wide visualization, close to the target and inside the anatomy. The panoramic view provided by the endoscope, allowing the identification of all the landmarks around the sella during the entire procedure, minimizes the chance of an inaccurate orientation.

Keywords: Endonasal Endoscopic, Microscopic Transsphenoidal Approaches, Management of Pituitary Adenomas.

\section{INTRODUCTION}

Among all the intracranial tumors, pituitary adenomas represent the third most common lesion, with a prevalence of
$16.9 \%$ in autopsy studies (Ezzat et al., 2014). The management of these lesions can become particularly challenging especially in those classified as large or 


\section{Osama Abd El-Kader El-Moursi et al.,}

giant and with wide intracranial extension or prevalent inferior involvement down into the nasal and paranasal cavities (Cappabianca et al., 2012).

The operative microscope soon became the standard for transsphenoidal pituitary tumor resections. The mid 1990's saw the emergence of rigid endoscopes for resection of pituitary tumors (Gamea et al., 2010). Shortly after its introduction, several institutions began to transition to endoscopic techniques due to the improved visualization provided by the endoscope's wider and angled views (Zaidi et al., 2016).

Proponents of the endoscopic approach believe that the improved visualization and additional lighting allows for better differentiation between tumor and normal gland, which may improve preservation of pituitary function and increase extent of tumor resection (EOR) (Cavallo et al., 2012).

Immediately following its introduction, expanded endonasal approaches to intracranial lesions faced substantial criticism due to their high risk of postoperative cerebrospinal fluid (CSF) leak and the perceived risk of intracranial infection with sinonasal flora. Progressive development of the technique, led by multiple pioneering centers around the world, reduced these pertinent concerns. We are approaching the 10th anniversary of the pedicled nasoseptal flap, which was quickly adopted worldwide and dramatically reduced postoperative CSF leak rates, making the technique reliable and reproducible. Furthermore, the apprehension regarding high rates of postoperative infection proved to be unfounded. Consequently, endoscopic endonasal approaches (EEAs) to address intracranial diseases became a viable alternative to traditional approaches (Sinha et al., 2010).

The conventional transcranial approach has been traditionally the first choice for the removal of large intracranial adenomas, because of limited visualization beyond the sella provided by microscopic transsphenoidal approaches (Sinha et al., 2010).

The improved visualization gained with the introduction of the endoscope, adopted over the past two decades for the treatment of pituitary adenomas and other sellar lesions, has opened the possibility of removing lesions that grow considerably beyond the sella, thus greatly increasing the number of tumors being approached via the transsphenoidal route (Cappabianca et al., 2012).

In many neurosurgical centers worldwide, endoscopic approaches are routinely used in clinical practice ( $D i$ Maio et al., 2011).

The aim of the present work was assessment of patient outcomes regarding transsphenoidal endoscopic and microscopic approaches of pituitary adenomas.

\section{PATIENTS AND METHODS}

This present work was a comparative study between 2 different transsphenoidal approaches to pituitary adenomas; endoscopic and microscopic. Data were collected retrospectively mainly but also prospectively for all patients who underwent either microscopic or endoscopic transsphenoidal resection of pituitary tumors over period of 2 years. 
Total 40 adult patients were included in our study, divided into 2 equal groups: group A underwent microscopic surgery, while group B underwent endoscopic one.

Patient inclusion criteria included adult patients, having macroadenoma with mass effect, prolactinomas with prolactin level > $150 \mathrm{ng} / \mathrm{dl}$ not responding to medical treatment, other functioning adenomas like acromegaly and Cushing's disease. Also, at least 6 months follow up after surgery was required.

Exclusion criteria was children, nonfunction adenoma with no mass effect and deemed more suitable for conservative management, prolactinomas responding to medical treatment and patients with less than 6 months follow up after surgery.

Preoperatively, all patients had full endocrinology assessment including prolactin, IGF-1, GH, ACTH, fasting 8 am cortisol level, TSH, free T3 and T4, LH and FSH. Other tests were done if needed including oral glucose suppression test and overnight dexamethasone suppression test in cases of acromegaly and Cushing's disease respectively.

Full visual assessment also was done including visual field, visual acuity and fundus examination.

All patients had preoperative MRI pituitary gland with $\mathrm{T} 1, \mathrm{~T} 2$, and $\mathrm{T} 1$ post contrast sequences and CT nasal sinuses to aid the preoperative planning.

Postoperatively, all patients underwent endocrinological evaluation at 2 weeks, 6 weeks and 6 months. MRI was repeated after 6 months. Regarding secreting tumors, relevant endocrinological tests were done. Hospital stay, operative time, extends on intraoperative exposure, postoperative complications.

The microscopic approach was performed by a neurosurgeon experienced in the transseptal route, whereas the endoscopic approach, employed the 2 nostril, 4 hand technique performed by a neurosurgeon and an otolaryngologist.

\section{Statistical analysis:}

Recorded data were analyzed using the statistical package for the social sciences, version 20.0 (SPSS Inc., Chicago, Illinois, USA). Quantitative data were expressed as range. Qualitative data were expressed as frequency and percentage. Chi-square (x2) test or Fisher's exact test of significance was used in order to compare proportions between two qualitative parameters. The confidence interval was set to $95 \%$ and the margin of error accepted was set to 5\%. P-value <0.05 was considered significant.

\section{RESULTS}

No statistically significant difference could be detected between both studied groups as regard presenting symptoms. Headache was the commonest presenting symptom in both endoscopic and microscopic groups $(60 \% \& \quad 70 \%$ respectively) followed by visual impairment (55\%\& $60 \%$ respectively). Although, loss of libido was the most common endocrinopathies (75\% \& 60\% 
respectively). The most common type of sphenoid sinus in both groups was the sellar type, followed by the conchal and presellar types. The sphenoid sinus septa could be easily described from CT images whether single or multiple. The sellar floor was intact in $40 \%$ of endoscopic cases and in $60 \%$ of microscopic cases.
No statistically significant difference could be detected between both studied groups as regard preoperative CT findings. Endocrinopathies were the most common indication followed by failure of previous management then visual or cranial nerve affection, while hydrocephalus came in the last (Table 1).

Table (1): Age, sex range, previous management, endocrinopathies, preoperative CT findings and indication for surgery in both studied groups

\begin{tabular}{|c|c|c|c|}
\hline \multicolumn{2}{|c|}{$\begin{array}{ll}\text { Parameters } & \text { Groups } \\
\end{array}$} & $\begin{array}{c}\text { Endoscopic group } \\
(\mathrm{N}=\mathbf{2 0})\end{array}$ & $\begin{array}{c}\text { Microscopic } \\
\text { group }(\mathbf{N}=20)\end{array}$ \\
\hline \multicolumn{2}{|c|}{ Age } & 24 years -65 years & 28 years- 60 years \\
\hline \multicolumn{2}{|c|}{ Sex } & 10 male -10 female & 12 male -8 female \\
\hline \multirow{4}{*}{$\begin{array}{c}\text { Previous } \\
\text { management }\end{array}$} & Medical & $3(15 \%)$ & $4(20 \%)$ \\
\hline & Surgical & $6(30 \%)$ & $4(20 \%)$ \\
\hline & G- knife & $2(10 \%)$ & $3(15 \%)$ \\
\hline & Non & $9(45 \%)$ & $9(45 \%)$ \\
\hline \multirow{9}{*}{ Endocrinopathies } & Headache & $12(60 \%)$ & $14(70 \%)$ \\
\hline & Field & $10(50 \%)$ & $11(55 \%)$ \\
\hline & Fundus & $4(20 \%)$ & $5(25 \%)$ \\
\hline & Visual & $11(55 \%)$ & $12(60 \%)$ \\
\hline & Acromegaly & $4(20 \%)$ & $3(15 \%)$ \\
\hline & Cushing & $2(10 \%)$ & $2(10 \%)$ \\
\hline & Loss of lipido & $15(75 \%)$ & $12(60 \%)$ \\
\hline & $\begin{array}{l}\text { Amen/ galact } \\
\text { syndrome }\end{array}$ & $7(35 \%)$ & $6(30 \%)$ \\
\hline & Hypopituitarism & $4(20 \%)$ & $5(25 \%)$ \\
\hline \multirow{3}{*}{$\begin{array}{l}\text { Preoperative CT } \\
\text { findings }\end{array}$} & $\begin{array}{c}\text { Type of } \\
\text { sphenoid sinus } \\
\text { Sellar } \\
\text { Presellar } \\
\text { Conchal }\end{array}$ & $\begin{array}{c}13(65 \%) \\
3(15 \%) \\
4(20 \%)\end{array}$ & $\begin{array}{l}14(70 \%) \\
2(10 \%) \\
4(20 \%)\end{array}$ \\
\hline & $\begin{array}{l}\text { Sellar floor } \\
\text { Intact } \\
\text { Not intact }\end{array}$ & $\begin{array}{c}8(40 \%) \\
12(60 \%)\end{array}$ & $\begin{array}{l}12(60 \%) \\
8(40 \%)\end{array}$ \\
\hline & $\begin{array}{c}\text { Sphenoid sinus } \\
\text { septum } \\
\text { Single } \\
\text { multiple }\end{array}$ & $\begin{array}{l}10(50 \%) \\
10(50 \%)\end{array}$ & $\begin{array}{l}11(55 \%) \\
9(45 \%)\end{array}$ \\
\hline \multirow{4}{*}{$\begin{array}{l}\text { Indication for } \\
\text { surgery }\end{array}$} & $\begin{array}{c}\text { Failure of } \\
\text { previous } \\
\text { management }\end{array}$ & $8(40 \%)$ & $11(55 \%)$ \\
\hline & $\begin{array}{l}\text { Visual or Cranial } \\
\text { nerve affection }\end{array}$ & $10(50 \%)$ & $13(65 \%)$ \\
\hline & Hydrocephalus & $1(5 \%)$ & $2(10 \%)$ \\
\hline & Endocrinopathies & $1680 \%)$ & $15(75 \%)$ \\
\hline
\end{tabular}


Nasal complications were more common among microscopic group compared to endoscopic group with significant difference in between by chisquare test. CSF leak occurred in 3 microscopic cases versus 4 endoscopic cases. Yet, meningitis was not recognized

as one of postoperative sequelae in this study. Headache was the most common symptom to improve postoperative both in microscopic and endoscopic groups; 71 and $100 \%$ with a significant difference in between by chi-square test (Table 2).

Table (2): Postoperative complications and postoperative improvement

\begin{tabular}{|c|c|c|c|c|}
\hline \multicolumn{2}{|c|}{$\begin{array}{ll}\text { Parameters } & \text { Groups } \\
\end{array}$} & $\begin{array}{c}\text { Endoscopic, } \\
\mathbf{N}=20\end{array}$ & $\begin{array}{c}\text { Microscopic, } \\
\mathbf{N}=\mathbf{2 0}\end{array}$ & $\mathbf{P}$ \\
\hline \multirow{7}{*}{$\begin{array}{l}\text { Postoperative } \\
\text { complications }\end{array}$} & Diabetes insipidus & $4(20 \%)$ & $3(15 \%)$ & $>0.05$ \\
\hline & CSF leak & $4(20 \%)$ & $3(15 \%)$ & $>0.05$ \\
\hline & Nasal & $4(20 \%)$ & $15(75 \%)$ & $<0.001$ \\
\hline & Hypopituitarism & $3(15 \%)$ & $3(15 \%)$ & $>0.05$ \\
\hline & $\begin{array}{l}\text { Deterioration of } \\
\text { consciousness }\end{array}$ & $0(0 \%)$ & $0(0 \%)$ & $>0.05$ \\
\hline & Meningitis & $0(0 \%)$ & $0(0 \%)$ & $>0.05$ \\
\hline & $\begin{array}{c}\text { Visual } \\
\text { deterioration }\end{array}$ & $0(0 \%)$ & $2(10 \%)$ & $>0.05$ \\
\hline \multirow{4}{*}{$\begin{array}{l}\text { Postoperative } \\
\text { improvement }\end{array}$} & Visual & $9 / 11(82 \%)$ & $7 / 12(58 \%)$ & $>0.05$ \\
\hline & Fundus & $3 / 4(75 \%)$ & $1 / 5(20 \%)$ & $>0.05$ \\
\hline & Field & $6 / 10(60 \%)$ & $3 / 11(27 \%)$ & $>0.05$ \\
\hline & Headache & $12 / 12(100 \%)$ & $10 / 14(71 \%)$ & $>0.05$ \\
\hline
\end{tabular}

Hormonal control was better achieved with endoscopic approach with best results seen with prolactinomas (Table 3).

Table (3): Post-operative hormonal improvement

\begin{tabular}{|c|c|c|c|}
\hline \multirow{2}{*}{ Hormonal Level } & Groups & Endoscopic & Microscopic \\
\hline \multirow{2}{*}{$\begin{array}{c}\text { Improved to } \\
\text { normal }\end{array}$} & Prolactin & $5 / 5(100 \%)$ & $5 / 6(84 \%)$ \\
\cline { 2 - 4 } & ACTH & $4 / 5(80 \%)$ & $4 / 6(66 \%)$ \\
\cline { 2 - 4 } & GH & $4 / 5(80 \%$ & $5 / 6(84 \%)$ \\
\hline \multirow{3}{*}{ Improved } & Prolactin & $0 / 5(0 \%)$ & $1 / 6(16 \%)$ \\
\cline { 2 - 4 } & ACTH & $1 / 5(20 \%)$ & $2 / 6(33 \%)$ \\
\cline { 2 - 4 } & GH & $1 / 5(20 \%)$ & $1 / 6(16 \%)$ \\
\cline { 2 - 4 } & TSH & $1 / 5(20 \%)$ & $0 \%$ \\
\hline
\end{tabular}

Concerning postoperative radiological (MRI) follow-up, tumor resection was divided into either total (refers to a complete gross total removal) or subtotal (anything less). Comparing both study groups exposes $80 \%$ total resection in endoscopic group versus $55 \%$ in microscopic group with significant difference in between by chi-square test (Table 4). 
Table (4): Postoperative radiological improvement

\begin{tabular}{|c|c|c|c|}
\hline $\begin{array}{c}\text { Gmprovement } \\
\text { (Radiological) }\end{array}$ & $\begin{array}{c}\text { Groups } \\
\mathbf{N = 2 0}\end{array}$ & $\begin{array}{c}\text { Microscopic, } \\
\mathbf{N = 2 0}\end{array}$ & $\mathbf{P}$ \\
\hline Subtotal resection & $4 / 20(20 \%)$ & $9 / 20(45 \%)$ & $>0.05$ \\
\hline Total resection & $16 / 20(80 \%)$ & $11 / 20(55 \%)$ & $>0.05$ \\
\hline
\end{tabular}

\section{DISCUSSION}

Our study included 40 cases of pituitary adenomas, operated upon during 2 years, half of them (group A; 20 cases) underwent endoscopic endonasal transsphenoidal pituitary adenoma resection, while the remaining (group $\mathrm{B}$; 20 cases) operated upon using the standard microscopic transseptal transsphenoidal pituitary adenoma resection.

Selection between both groups (group A\& B) and choice of the surgical approach was in a random order according to surgeon preference and expertise. The highest age incidence of our cases was during the third and fourth decades of life, with a male to female ratio of nearly $1: 1$ and this coincides with the findings of (Greenberg, 2011).

Headache was the commonest presenting symptom in our series both in endoscopic and microscopic groups; $(60 \% \& 70 \%)$ respectively followed by visual impairment; (55\%\& 60\%). Although, loss of libido was the most common endocrinopathies; (75\%\& 60\%) respectively. This coincides with the findings of (Blevins et al., 2010 and Cavallo, 2012).

In our study, visual complaints were encountered in the form of diminution of vision, which was bilateral in all cases and was accompanied with bitemporal hemianopia in almost all cases presenting with diminution of vision. While all hormonally active adenomas presented with endocrinal manifestations in the form of acromegaly, amenorrhea/ galactorrhea syndrome in female, loss of libido and impotence in male, and Cushing syndrome. This coincides with the findings of (Blevins et al., 2010).

In our study, CT-sella with coronal cuts was the initial radiographic investigation, performed in all our cases. It gave an idea about bony anatomy of the sella, sphenoid sinus, and particularly was important in showing the position of the sphenoid sinus septum, which was crucial in planning the decision of operation. Throughout the study, MRI brain with and without contrast was performed before surgery in all patients as the main tool used for identification of the soft tissue relations of the tumor. MRI was also the main tool used throughout the study to judge the extent of surgical radicality being a more solid and reliable evidence. Also, Blevins et al. (2010) suggested the use of MRI as the main tool to judge surgical radicality. There was no constant relationship between tumor size and preoperative hormone levels, however, the larger tumors showed a higher level of preoperative prolactin especially in cases with cavernous sinus invasion for prolactin secreting adenomas. Also, there was no relationship between the MRI findings and the pathological nature of the. We performed follow-up MRI 3 
months postoperatively. However; Yoon et al. (2011) advocates early postoperative MR imaging; as it is useful in the detection of residual tumor. Since the early postoperative sella retains its preoperative volume, one can easily differentiate residual tumor from a normal gland, implanted materials, or postsurgical granulation tissue. In addition, early postoperative MR images can be an excellent baseline if radiation therapy is necessary for treatment of residual tumor or recurrent tumor suspected on follow-up MR images.

In our study, prolactin level improved significantly in all cases of. Analysis of the hormonal profile results showed better results in endoscopic than microscopic group.

We found that the endoscope enabled better differentiation between tumor and normal pituitary tissue than the operating microscope, also better sight of residual cavity after tumor removal and these coincide with Gamea et al. (2010) who emphasized that the endoscope was helpful for tumor micro-dissection with excellent panoramic vision. Batay et al. (2012) performed a comparative study of an outlook obtained from an extended transsphenoid approach on 10 cadavers using both endoscope and microscope, a larger exposure was provided by the endoscope than by the operating microscope while measuring the horizontal and vertical extent. Spencer et al. (2010) had contributed through quantifying and comparing the "volumes of view" of the endoscope and microscope in the setting of pituitary surgery. In their anatomical study of surgical approaches to the pituitary gland, they were able to objectively demonstrate with statistical significance that the $0^{\circ}$ endoscope afforded more comprehensive views of the sella turcica than the microscope. Also, the longer operative distance was the main disadvantage in using the microscope. A surgeon inexperienced with the technique may become frustrated by the small operating space.

Complications in the fully endoscopic procedure can be almost completely avoided with careful technique. Incidence of morbidity is related to injuries to the normal gland or to surrounding neurovascular structures.

Throughout this study, complications associated with endoscopic surgery were, in general, fewer than with microsurgery as there was less wound trauma with the endoscopic approach resulted in less nasal complications. No patients with nasal septum perforation, sinusitis, and gum wound disruption or massive nasal bleeding. Batay et al. (2012) reported that $85 \%$ of patients with endoscopic hypophysectomy were satisfied with their nasal airways postoperatively, they had no operative infections. Improved visualization allowed the surgeon to identify and avoid injury to the normal pituitary, carotid prominences, hypothalamus and optic chiasm leading to fewer complications with better out-come. The incidence of sinusitis was higher in microscopic group, because the trauma to the sphenoid sinus and nasal cavity are greater. Visual deterioration was more common among microscopic group compared to endoscopic group. We distinguished four cases with diabetes insipidud in endoscopic group vs. three cases in microsurgery, also four cases 


\section{Osama Abd El-Kader El-Moursi et al.,}

with CSF leak comparing to three for microscopic group, and this does not equivalent to what Koren et al. (2011). Louis et al. (2014) reported the incidence of various complications in both groups was recorded, and the results were compared to those from a national survey by Ciric et al. (2010). Our results were nearly parallel in the microscopic group, with reduction in the incidence of sinonasal complications in endoscopic group.

In our study, improvement in out-come was higher in endoscopic group opposed to microscopic group. Sheehan et al. (2011) compared a group of patients who underwent the sublabial approach with a group who were operated endoscopically and found no differences in out-come regarding vision and anterior pituitary function. Cappabianca et al. (2012) found improved out-come of endoscopic group against microscopic one regarding tumor excision and hormone imbalance. Jho and Carrau (2010) reported similar results. Preliminary evidence suggests that complication rates and surgical outcomes of our microscopic group were nearly parallel to those that have been reported in large series of transsphenoidal microscopic pituitary surgeries.

\section{CONCLUSION}

Endoscopy offers a very special and wide visualization, close to the target and inside the anatomy. The panoramic view provided by the endoscope, allowing the identification of all the landmarks around the sella during the entire procedure, minimizes the chance of an inaccurate orientation.

\section{REFERENCES}

1. Batay F, Vural E, Karasu A and Al-Mefty O. (2012): Comparison of the exposure obtained by endoscope and microscope in the extended trans-sphenoidal approach. Official Journal of North American Skull Base Society, 12(3):119-24.

2. Blevins LS, Christy JH, Khajavi $M$ and Tindall GT. (2010): Outcomes of Therapy for Cushing's Disease due to AdrenocorticotropinSecreting Pituitary Macroadenomas. The Journal of Clinical Endocrinology \& Metabolism, 83(1):63-66.

3. Cappabianca P, Cavallo LM, Esposito F, De Divitiis O, Messina A and De Divitiis E. (2012): Extended endoscopic endonasal approach to the midline skull base: the evolving role of transsphenoidal surgery. Adv Tech Stand Neurosurg., 33:151-99.

4. Cavallo LM, Prevedello D, Esposito F, Laws ER, Dusick JR and Messina A. (2012): The role of the endoscope in the transsphenoidal management of cystic lesions of the sellar region. Neurosurgical Review, 31(1):55-64.

5. Ciric I, Ragin A, Baumgartner C, Pierce D. (2010): Complications of transsphenoidal surgery: results of a national survey, review of the literature, and personal experience. Neurosurgery, 40(2):225-36.

6. Di Maio S, Cavallo LM, Esposito F, Stagno V, Corriero OV and Cappabianca P. (2011): Extended endoscopic endonasal approach for selected pituitary adenomas: early experience. $\mathbf{J}$ Neurosurg., 114(2):345-53.

7. Gamea A, Fathi M and El-Guindy A. (2010): The use of the rigid endoscope in transsphenoidal pituitary surgery. The Journal of Laryngology and Otology, 108(1):19-22.

8. Greenberg MS. (2011): Handbook of neurosurgery. Neuroophthalmology, 35(1): 5459.Pbl. New York: Thieme.

9. Jho HD and Carrau RL. (2010): Endoscopic endonasal transsphenoidal surgery: experience with 50 patients. J Neurosurg., 87(1):44-51.

10. Koren I, Hadar T, Rappaport ZH and Yaniv E. (2011): Endoscopic transnasal transsphenoidal microsurgery versus the 
sublabial approach for the treatment of pituitary tumors: endonasal complications. Laryngoscope, 109(11):1838-40.

11. Louis RG, Eisenberg A, Barkhoudarian G, Griffiths C and Kelly DF. (2014): Evolution of minimally invasive approaches to the sella and parasellar region. Int Arch Otorhinolaryngol., 18(2):136-48.

12. Sheehan MT, Atkinson JL, Kasperbauer JL, Erickson BJ and Nippoldt TB. (2011): Preliminary comparison of the endoscopic transnasal vs the sublabial transseptal approach for clinically nonfunctioning pituitary macroadenomas. Mayo Clinic Proceedings, 74(7):661-70.

13. Sinha $S$ and Sharma BS. (2010): Giant pituitary adenomas--an enigma revisited. Microsurgical treatment strategies and outcome in a series of 250 patients. Br J Neurosurg., 24(1):31-9.
14. Spencer WR, Das K, Nwagu C, Wenk E, Schaefer SD and Moscatello A. (2010): Approaches to the sellar and parasellar region: anatomic comparison of the microscope versus endoscope. Laryngoscope, 109(5):791-4.

15. Yoon PH, Kim DI, Jeon P, Lee SI, Lee SK and Kim SH. (2011): Pituitary adenomas: early postoperative MR imaging after transsphenoidal resection. AJNR American Journal of Neuroradiology, 22(6):1097-104.

16. Zaidi HA, Awad AW, Bohl MA, Chapple K, Knecht $L$ and Jahnke H. (2016): Comparison of outcomes between a less experienced surgeon using a fully endoscopic technique and a very experienced surgeon using a microscopic transsphenoidal technique for pituitary adenoma. J Neurosurg., 124(3):596604. 


\section{در اسة مقارنة بين طرق التتظير الداخلي الأنفي و المبكروسكوبية عبر العقد في علاج أورام الغدة النخامبة أسامة عبد القادر محمد المرسي, عبد الباسط علي صالح, مجدي الهواري} قسم جراحة المخ والأعصاب, كلية الطب، جامعة الأزهر

E-mail: $\underline{\text { osama_abdelkader@gmail.com }}$

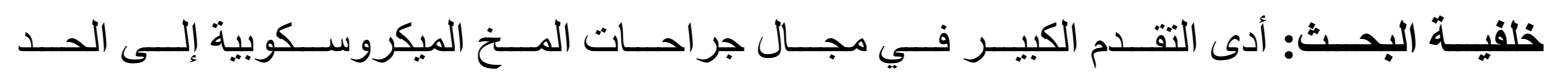

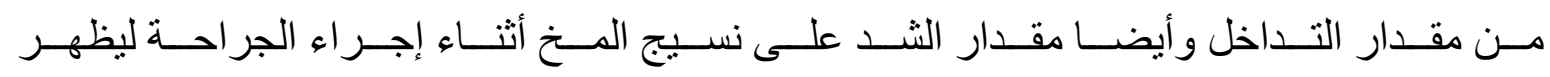

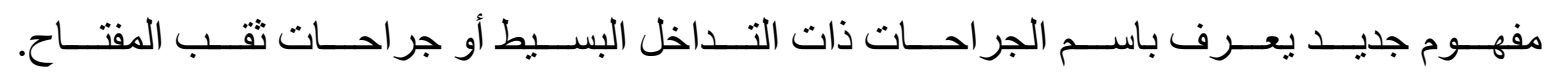

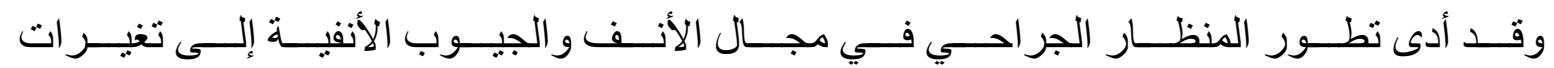

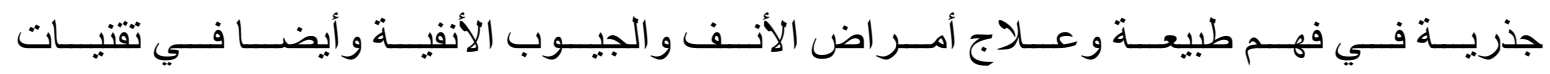
الجراحة.

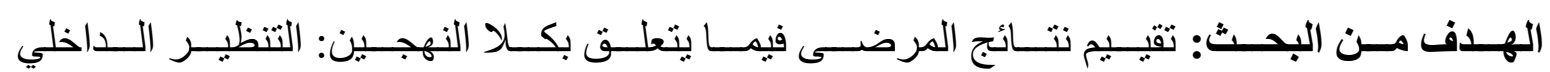
الأنفي و الميكروسكو بية عبر العقد في علاج أورام الغدة النخامية.

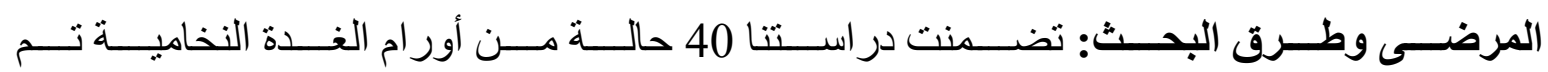

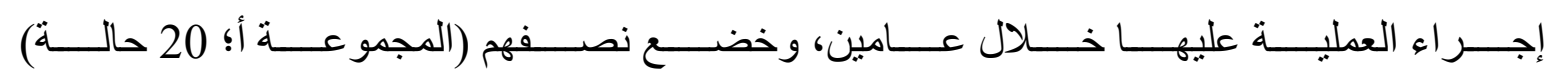

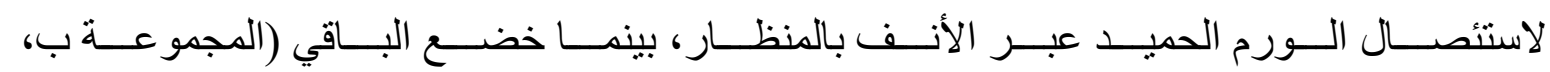

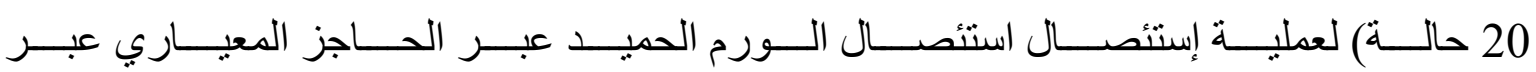
الحاجز المعباري.

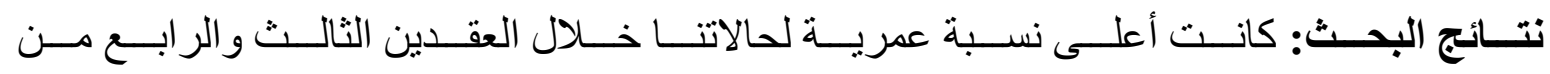

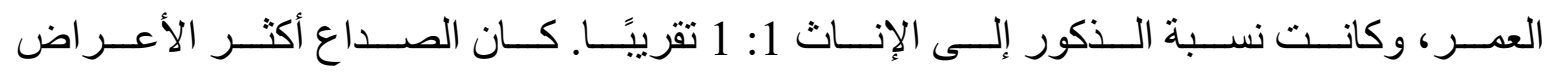

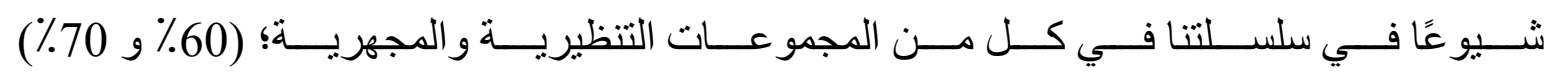

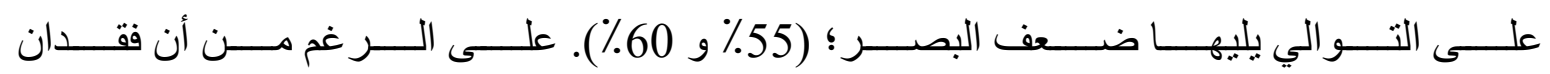

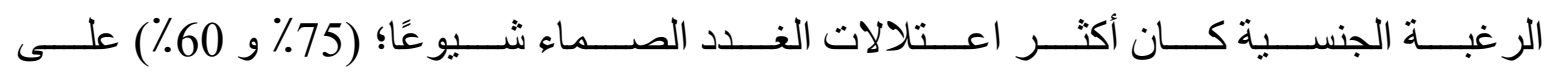

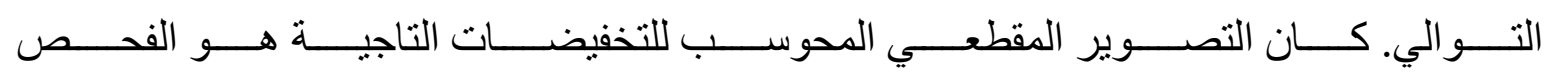

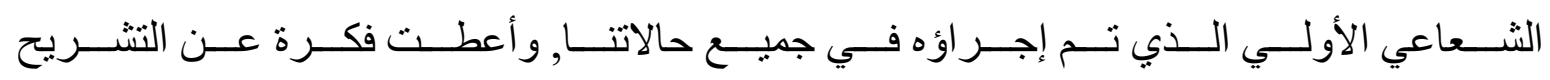

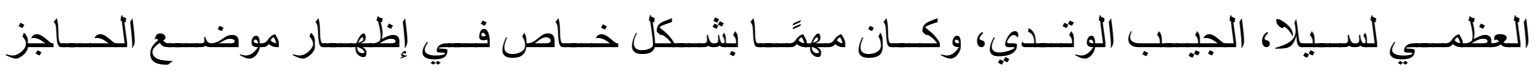




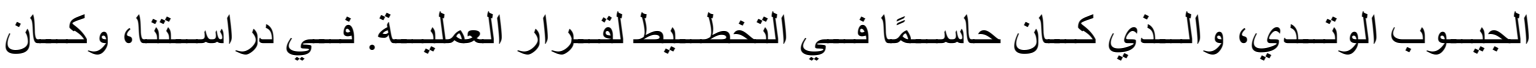

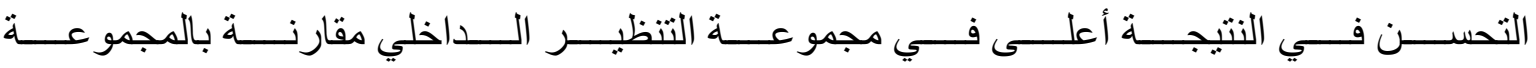

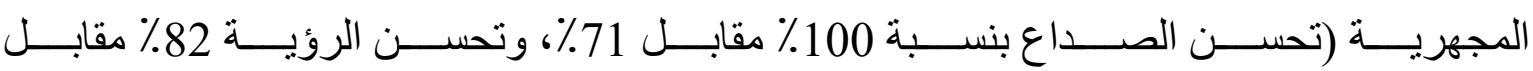
58٪، و 80\% مقابل إزالة الورم الكلي بنسبة 55\%).

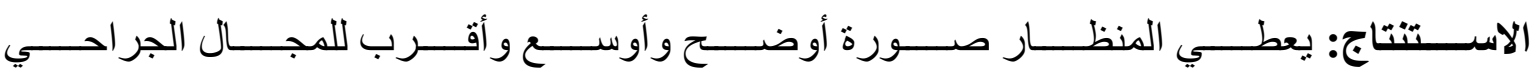

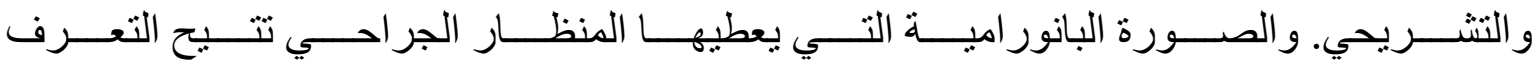

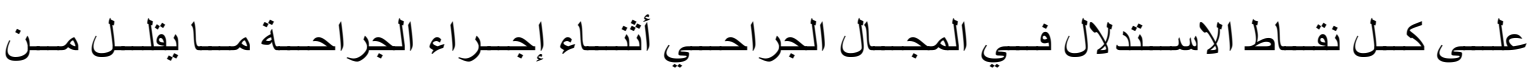
إحتمالية التوجيه الغير دقيق.

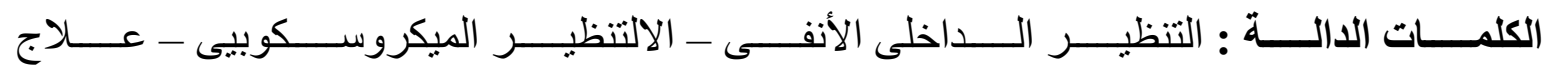
أورام الغدة النخامبة . 